\title{
Análise ultraestrutural e de fatores de crescimento de diferentes métodos de preservação da membrana amniótica utilizada em cirurgia ocular
}

\author{
Ultrastructural and growth factor analysis of amniotic membrane preserved \\ by different methods for ocular surgery
}

\author{
Janethe Deolinda de Oliveira Pena ${ }^{1}$ \\ Gustavo Barreto de Melo 2 \\ José Álvaro Pereira Gomes ${ }^{3}$ \\ Edna Freymuller Haapalainen ${ }^{4}$ \\ Ciro Massayuki Komagome ${ }^{5}$ \\ Namir Clementino Santos ${ }^{6}$ \\ Acácio Alves de Souza Lima Filho ${ }^{7}$ \\ Luiz Vicente Rizzo ${ }^{8}$
}

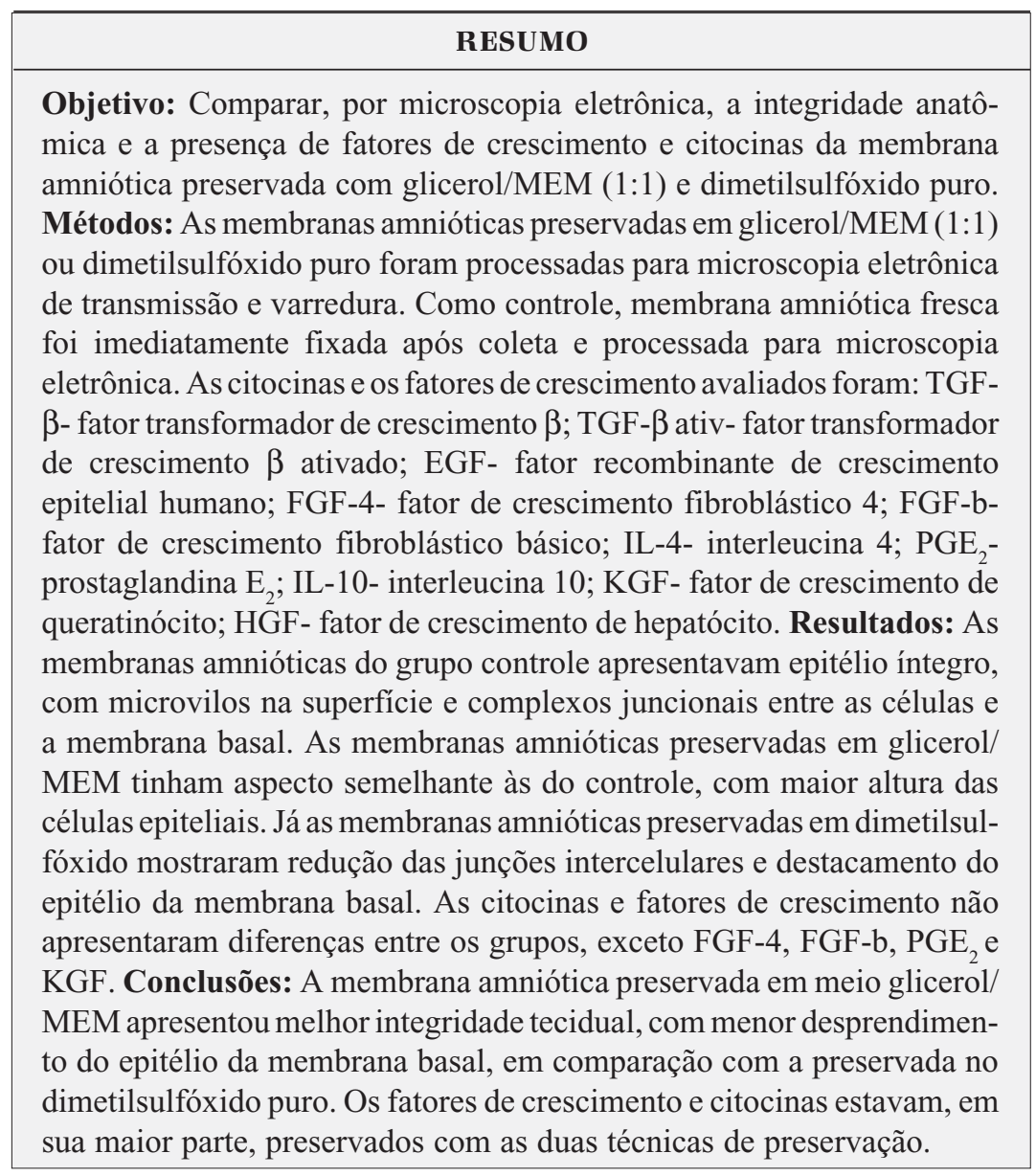

Trabalho realizado no Departamento de Oftalmologia da Universidade Federal de São Paulo - UNIFESP - São Paulo (SP) - Brasil.

Doutora em Ciências Visuais pela Universidade Federal de São Paulo - UNIFESP - São Paulo (SP) - Brasil; Professora Docente do Departamento de Imunologia da Universidade Federal de Uberlândia - UFU - Uberlândia (MG) - Brasil.

${ }^{2}$ Médico Residente do Departamento de Oftalmologia da UNIFESP - São Paulo (SP) - Brasil.

${ }^{3}$ Professor Afiliado do Departamento de Oftalmologia, Diretor do Centro Avançado de Superfície Ocular (CASO) do Instituto da Visão da UNIFESP - São Paulo (SP) - Brasil.

${ }^{4}$ Professora Livre-Docente, Diretora do Centro de Microscopia Eletrônica da UNIFESP - São Paulo (SP) Brasil.

Oftalmologista do Departamento de Oftalmologia da UNIFESP - São Paulo (SP) - Brasil.

${ }^{6}$ Oftalmologista do setor de Córnea e Doenças externas do Departamento de Oftalmologia da UNIFESP - São Paulo (SP) - Brasil.

Chefe do setor de Farmacologia Ocular do Departamento de Oftalmologia da UNIFESP - São Paulo (SP) - Brasil.

${ }^{8}$ Professor Titular do Departamento de Imunologia da Universidade de São Paulo - USP - São Paulo (SP) Brasil.

Endereço para correspondência: José Álvaro Pereira Gomes. Departamento de Oftalmologia da Universidade Federal de São Paulo. Rua Botucatu, 822 - São Paulo (SP) CEP 04023-062 - E-mail: japgomes@uol.com.br

Este trabalho é parte de Projeto Temático financiado pela FAPESP

Recebido para publicação em 01.02.2007

Aprovação em 21.07.2007

Nota Editorial: Depois de concluída a análise do artigo sob sigilo editorial e com a anuência dos Drs. Samuel Rymer e Hélia Soares Angotti sobre a divulgação de seus nomes como revisores, agradecemos suas participações neste processo.
Objetivo: Comparar, por microscopia eletrônica, a integridade anatômica e a presença de fatores de crescimento e citocinas da membrana amniótica preservada com glicerol/MEM (1:1) e dimetilsulfóxido puro. Métodos: As membranas amnióticas preservadas em glicerol/MEM (1:1) ou dimetilsulfóxido puro foram processadas para microscopia eletrônica de transmissão e varredura. Como controle, membrana amniótica fresca foi imediatamente fixada após coleta e processada para microscopia eletrônica. As citocinas e os fatores de crescimento avaliados foram: TGF$\beta$ - fator transformador de crescimento $\beta$; TGF- $\beta$ ativ- fator transformador epitelial humano; FGF-4- fator de crescimento fibroblástico 4; FGF-bfator de crescimento fibroblástico básico; IL-4- interleucina 4; $\mathrm{PGE}_{2}$ prostaglandina $\mathrm{E}_{2}$; IL-10- interleucina $10 ; \mathrm{KGF}$ - fator de crescimento de queratinócito; HGF- fator de crescimento de hepatócito. Resultados: As

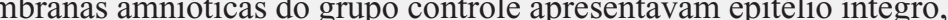
a membrana basal. As membranas amnióticas preservadas em glicerol/ MEM tinham aspecto semelhante às do controle, com maior altura das celulas epiteliais. Já as membranas amnióticas preservadas em dimetilsuloxido mostraram redução das junções intercelulares e destacamento do apresentaram diferenças entre os grupos, exceto FGF-4, FGF-b, PGE 2 KGF. Conclusões: A membrana amniótica preservada em meio glicerol/ MEM apresentou melhor integridade tecidual, com menor desprendimendimetilsulfóxido puro Os fatores de crescimento e citocinas estavam, em

Descritores: Âmnio; Microscopia eletrônica; Glicerol; Dimetilsulfóxido; Citocina; Fator transformador de crescimento beta

\section{INTRODUÇÃO}

A membrana amniótica vem sendo rotineiramente utilizada em oftalmologia no tratamento de afecções da superfície ocular, como defeitos corneanos persistentes ou recorrentes ${ }^{(1-2)}$ perfurações corneanas ${ }^{(2-4)}$, reconstruções conjuntivais $^{(5)}$, como enxerto após a remoção cirúrgica de pterígio e tumores ${ }^{(5)}$, simbléfaros severos ${ }^{(6)}$, como oclusor de pontos lacri- 
mais em casos de olho seco ${ }^{(2)}$, no tratamento de bolhas filtrantes com vazamentos ${ }^{(4,7)}$ e nas reconstruções palpebrais ${ }^{(8)}$.

Em um modelo experimental de deficiência total de limbo em olhos de coelhos, foi observado que $77 \%$ dos animais que foram submetidos ao transplante de membrana amniótica apresentaram recuperação total ou parcial da superfície ocu$\operatorname{lar}^{(9)}$. O grupo controle, que não recebeu membrana amniótica, desenvolveu vascularização e opacidade corneanas em $100 \%$ dos casos. Esses excelentes resultados podem ser explicados pelas características inatas da membrana amniótica, que possui uma membrana basal espessa e propriedades antiinflamatórias, antiapoptóticas e inibitórias da cicatrização, provavelmente relacionadas à presença e/ou inibição de fatores de crescimento ${ }^{(9-12)}$.

No início do seu uso, dificuldades técnicas quanto à sua preservação foram os principais empecilhos. Inicialmente, a membrana era tratada com etanol e óleo mineral, geralmente associados à esterilização por fervura ou em autoclave, sendo depois estocada seca ou em etanol a $70 \%$ até o uso. A membrana seca nem sempre apresentava bons resultados cirúrgicos. Assim, passou-se a simplesmente lavá-la e preservá-la em solução salina por até 72 horas. Com o advento dos antibióticos, começou-se a lavá-la em solução salina contendo antibióticos e preservada em solução contendo hipoclorito de sódio ou antibióticos. Com essa técnica, puderam ser, pela primeira vez, armazenadas por até 6 semanas em refrigerador ${ }^{(13-14)}$.

Recentemente, dois métodos têm sido mais utilizados para a preservação da membrana amniótica: dimetilsulfóxido (DMSO) e glicerol. Ambos têm a vantagem de serem crioprotetores, possibilitando o congelamento do tecido com pouca perda da viabilidade tecidual. Meio contendo glicerol a $20 \%$ foi um dos primeiros testados, com resultados satisfatórios ${ }^{(15)}$. DMSO também tem sido utilizado para preservação da membrana amniótica com bons resultados ${ }^{(6,10-11,16)}$.

Apesar do crescente interesse do uso da membrana amniótica em oftalmologia, os mecanismos envolvidos nas suas diversas propriedades, como os efeitos antiangiogênico, antiinflamatório e anti-cicatrizante, ainda não estão bem esclarecidos. Vários estudos têm demonstrado que o tecido amniótico produz e/ou modula a ação de uma série de citocinas (fatores de crescimento, interleucinas) ${ }^{(17-21)}$. IL-1 $\alpha$, IL-1 $\beta$ (interleucina pró-inflamatória) e receptor antagonista de IL-1 já foram demonstrados no fluido amniótico e em meio de cultura de células amnióticas ${ }^{(22)}$. IL-1 $\beta$ e a IL-4 são produzidas pelas células epiteliais amnióticas e parecem estar envolvidas na regulação da produção de algumas prostaglandinas relacionadas com o processo inflamatório, como a $\mathrm{PGE}_{4}$. Já foi demonstrado também que o tecido amniótico produz e expressa IL-10, citocina com potente efeito antiinflamatório $^{(23-24)}$. Estudos com ELISA e RT-PCR realizados utilizando a membrana amniótica preservada a $-80^{\circ} \mathrm{C}$ revelaram a presença de EGF, TGF- $\alpha$ e $\beta_{1,2,3}$, KGF, HGF e bFGF, relacionados com estimulação da epitelização (EGF, KGF, HGF, FGF), fibrose (TGF- $\beta$, KGF, FGF) e neovascularização (FGF) ${ }^{(19)}$.

Como não há estudos comparando a integridade estrutural e fatores de crescimento da membrana amniótica com essas técnicas, este trabalho objetivou compará-los entre os meios de preservação glicerol/MEM (1:1) e DMSO puro.

\section{MÉTODOS}

Coleta da membrana amniótica: A obtenção e o processamento da membrana amniótica foram realizados de acordo com as normas do protocolo aprovado pela Comissão de Ética da UNIFESP/EPM.

A membrana amniótica foi obtida a partir das placentas provenientes de cesáreas eletivas de pacientes do Hospital Maternidade Amparo Maternal, após consentimento assinado pelas gestantes. Todas essas pacientes tiveram exames sorológicos negativos para HIV-1, Hepatite B (HBsAg) e sífilis (VDRL), que foram re-confirmados pela realização de sorologia do sangue do cordão umbilical após o parto. Após 6 meses, novos testes foram repetidos nas mulheres.

Após a obtenção da placenta no centro cirúrgico obstétrico, procedeu-se à sua lavagem com o uso de soro fisiológico $0,9 \%$ em ambiente estéril. Posteriormente, o âmnio foi separado do córion com a utilização de tesoura e pinça estéreis e estendido sobre um filtro de nitrocelulose estéril (Millipore, Bedfort, MA, EUA) com a face epitelial para cima. A membrana e o filtro foram lavados com solução tampão fosfato contendo $1000 \mathrm{U} / \mathrm{ml}$ de penicilina, $20 \mathrm{mcg} / \mathrm{ml}$ de estreptomicina e $2,5 \mathrm{mcg} / \mathrm{ml}$ de anfotericina B (Ophthalmos, São Paulo), cortados em fragmentos de aproximadamente $3 \times 3 \mathrm{~cm}$, colocados em um recipiente estéril com o meio a ser estudado.

Preservação em glicerol/MEM (1:1): foram colocadas as membranas em solução de glicerol e meio de cultura de células MEM ("Minimal Essential Medium"), misturados na proporção $1: 1$, e congeladas a $-80^{\circ} \mathrm{C}$.

Preservação em DMSO: as membranas foram colocadas em dimetilsulfóxido (DMSO) puro e congeladas a $-80^{\circ} \mathrm{C}$.

Microscopia eletrônica de transmissão (MET): a membrana amniótica foi lavada em tampão cacodilato, $(0,1 \mathrm{M}$, pH 7) por 20 minutos para retirar o meio de preservação e foi colocada em fixador Karnovsky modificado (paraformaldeído $2 \%$, glutaraldeído 2,5\%) (Sigma Chemical, St. Louis, MO, EUA) por 30 minutos em temperatura ambiente e 16 horas $24 \mathrm{~h}, \mathrm{a} 4^{\circ} \mathrm{C}$. Após desprezar o fixador, o tecido foi deixado em tampão cacodilato $0,1 \mathrm{M}$ (EM Sciences, Philadelphia, PA, EUA) por 2 horas, com 4 trocas a $4^{\circ} \mathrm{C}$. Iniciou-se inclusão colocando o tecido em solução de ósmio a 2\% (EM Sciences, Philadelphia, PA, EUA) por $1 \mathrm{~h}$ em temperatura ambiente. $\mathrm{O}$ tecido foi lavado 2 vezes por 1 minuto, em água bidestilada e colocado em solução de acetato de uranila (uranila 0,5\% e sacarose 13,3\%) (EM Sciences, Philadelphia, PA, EUA) por 30 minutos em temperatura ambiente. Após duas lavagens em água bidestilada, o tecido foi desidratado em etanol $70 \%$ por 30 minutos, etanol $90 \%$ por 30 minutos e etanol $100 \%$ por 40 minutos. Colocou-se o tecido em óxido de propileno (EM Sciences, Philadelphia, PA, EUA) por 40 minutos, e, depois, 
em uma mistura de 2 partes de óxido de propileno para 1 parte de resina Araldite (EM Sciences, Philadelphia, PA, EUA) por 4 horas em agitador orbital. A resina foi desprezada e colocada no tecido na mistura de 1 parte de óxido de propileno para 1 parte de Araldite, que foi deixado sem tampa, por 16 às $18 \mathrm{~h}$, em agitador orbital. O tubo contendo tecido foi transferido em resina para câmara de vácuo por 4 a 5 horas e, depois, colocou-se cada peça do tecido em blocos próprios para MET. Cada peça de tecido foi deixada polimerizar a $60^{\circ} \mathrm{C}$ por 48 horas e foi seccionada em cortes finos $(0,3$ a $0,5 \mu \mathrm{m})$ e ultrafinos (70 a $90 \mathrm{~nm}$ ) para observação microscópica.

Microscopia eletrônica de varredura (MEV): após fixação em meio Karnovsky modificado (paraformaldeído 2\%, glutaraldeído $2,5 \%$ ), a membrana foi lavada em tampão cacodilatado $0,1 \mathrm{M}$, seguida por inclusão em solução de ósmio a $1 \%$ por 1 hora em temperatura ambiente. O tecido foi lavado por 30 minutos (3 trocas de 10 minutos cada) em tampão cacodilatado $0,1 \mathrm{M}$ e colocado em solução de ácido tânico a $1 \%$ por 30 minutos. Após 2 lavagens com água bidestilada, colocou-se o tecido em solução de ósmio a $1 \%$ por 30 minutos. $\mathrm{O}$ tecido foi lavado em água bidestilada por 15 minutos e desidratado em concentrações crescentes de etanol (50, 70, 90 e $100 \%, 30$ minutos cada). Com o material em etanol a $100 \%$, foi colocado em aparelho de ponto crítico (Balzers, modelo CPD-030). O material foi transferido para o "stub" metálico e submetido ao processo de metalização com ouro (aparelho de "sputtering"), Balzers, modelo SCD-050). Posteriormente, foi feita a análise por microscopia eletrônica de varredura.

Fatores de crescimento: fatores de crescimento, citocinas e prostaglandinas presentes nas membranas amnióticas foram medidos por ELISA utilizando kits previamente testados e disponíveis comercialmente.

Brevemente, fator recombinante de crescimento epitelial humano (EGF), fator de crescimento fibroblástico (FGF)-4, FGFbásico e fator de crescimento de hepatócito (HGF) foram testados utilizando kits da R\&D Systems (Minneapolis, MN, EUA). Medidas foram realizadas nos sobrenadantes das membranas frescas ou preservadas após 24 horas da captação. Em seguida, foram retiradas dos frascos com os meios respectivos e colocadas em meio de cultura (Serum-Free and protein-free hybridoma medium, Sigma Chemical Co. St. Louis, MO, EUA). As mesmas amostras foram congeladas e maceradas em diferentes momentos no mesmo meio de cultura (Serum-Free and protein-free hybridoma medium, Sigma Chemical Co. St. Louis, MO, EUA). As membranas maceradas foram colocadas em meio de cultura e os sobrenadantes avaliados após 24 horas. Fator de crescimento do queratinócito (KGF) foi medido utilizando um par de anticorpos da R\&D Systems: o anticorpo monoclonal MAB251, na concentração de $1,2 \mu \mathrm{g} / \mathrm{ml}$, que foi usado para revestir os fundos dos compartimentos da placa de ELISA; e o anticorpo secundário policlonal biontilado BAF251, seguido da adição de peroxidase (strepatavidin-horse radish peroxidase, HRPO) da Southern Biotechnologies Associates (Birmingham, AL, USA). A prostaglandina E2 (PGE2) foi medida utilizando um kit enzimático da Assay Designs Inc. (Ann Arbor, MI, EUA). Interleucina-4 humana (IL-4) e 10 (IL-10) foram medidas utilizando kits da Endogen (Cambridge, MA, USA). Fator transformador de crescimento beta (TGF- $\beta$ ) foi medido com o minikit da PROMEGA (Madison, WI, EUA). TGF- $\beta$ foi medido no sobrenadante da cultura antes e após ativação ácida como descrito nas instruções dos fabricantes. Também foi medido no sobrenadante da membrana amniótica tratada com solução não-enzimática para dissociação celular (Sigma Chemicals Co., St. Louis, MO, EUA).

\section{RESULTADOS}

\section{Microscopia eletrônica de transmissão}

Cortes transversais das membranas controles mostraram células epiteliais interconectadas através de complexos juncionais, com vacúolos intracelulares e microvilos na superfície apical. Na porção basal das células epiteliais, interdigitações foram observadas com a porção anterior da membrana basal, que dividia o epitélio do estroma colagenoso subjacente (Figuras 1A e 1B).

Em amostras de membrana amniótica preservada em meio glicerol/MEM, foi observado aumento da altura do epitélio e da espessura da membrana basal, com boa preservação das junções intercelulares e das interdigitações entre a face basal do epitélio e a membrana basal (Figuras 2A e 2B). Nas membranas preservadas com DMSO, foi evidenciada perda da integridade tecidual, com aumento da vacuolização das células epiteliais, diminuição das junções intercelulares, perda das interdigitações entre a face basal do epitélio e membrana basal e destacamento do epitélio da membrana basal (Figuras 3A e 3B).

\section{Microscopia eletrônica de varredura}

As membranas controles apresentavam superfície epitelial homogênea, com células poligonais bem próximas umas das outras. Delicados microvilos foram observados na superfície apical das células (Figura 1C). As membranas preservadas em glicerol/MEM apresentaram uma superfície também homogênea, com discreto aumento do espaço intercelular e microvilos foram observados na face apical do epitélio (Figura 2C). Em membranas preservadas em DMSO puro, foi observada perda da integridade epitelial, apresentando superfície mais globosa e formação de vesículas na superfície celular (Figura 3C).

\section{Fatores de crescimento}

As citocinas e fatores de crescimento tiveram níveis semelhantes entre os grupos controle, DMSO e glicerol/MEM, exceto FGF-4, FGF-b, PGE $_{2}$ e KGF (Figura 4).

\section{DISCUSSÃO}

Neste trabalho, apresentamos a comparação entre os efeitos de métodos de preservação diferentes sobre a membrana amniótica (glicerol/MEM e DMSO) sob o ponto de vista 


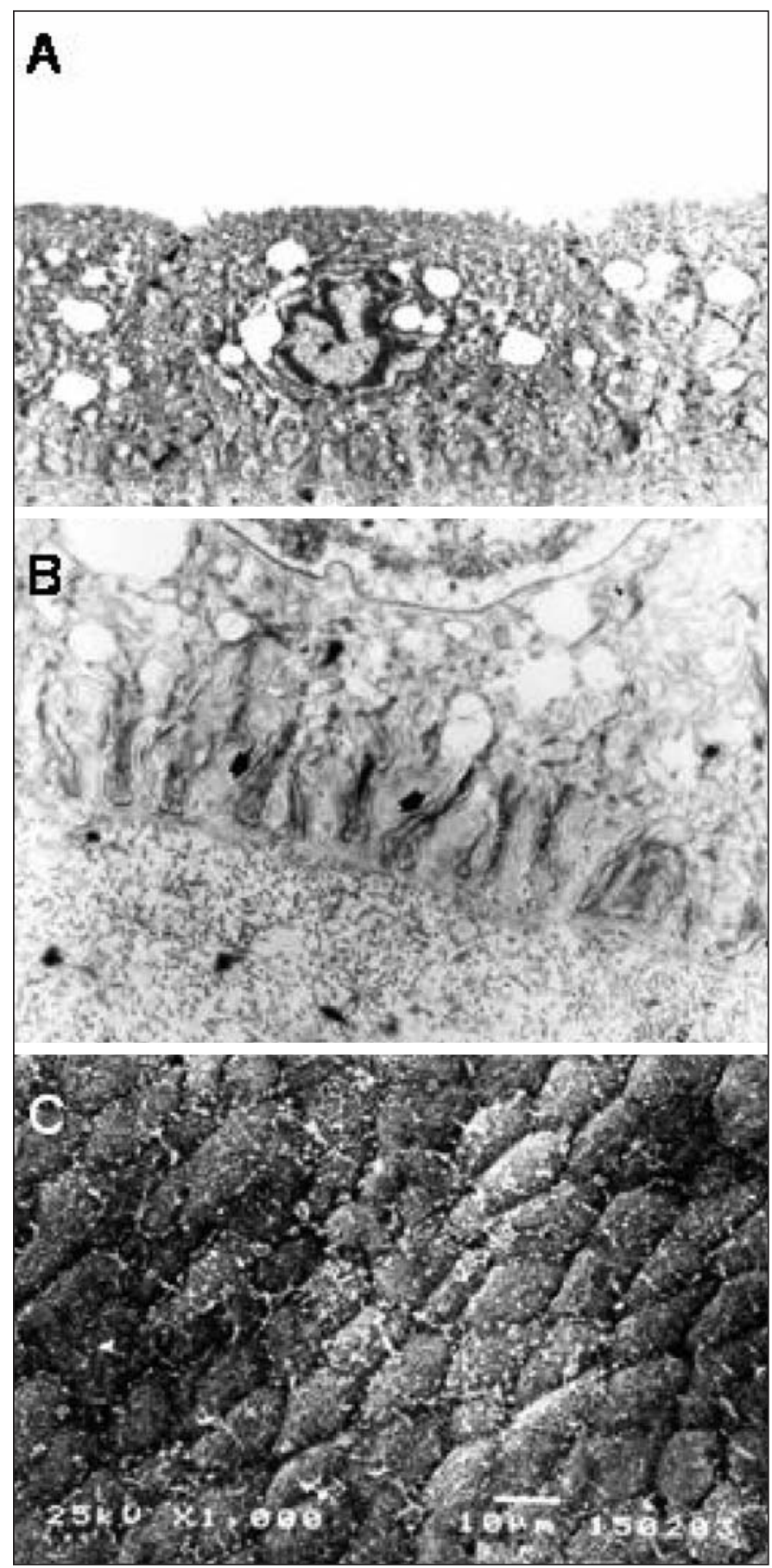

Figura 1 - Microscopia eletrônica das membranas frescas (controle). Em A e B, microscopia eletrônica de transmissão; em C, microscopia eletrônica de varredura.

estrutural e de fatores de crescimento. Ambos os métodos têm sido utilizados, mas não havia sido descrita, até então, a diferença entre eles.

Em um estudo em que o DMSO foi usado como meio de preservação, não foram avaliadas as propriedades ultra-estruturais da membrana amniótica. Apenas foram demonstradas suas propriedades antiinflamatórias ${ }^{(25)}$.
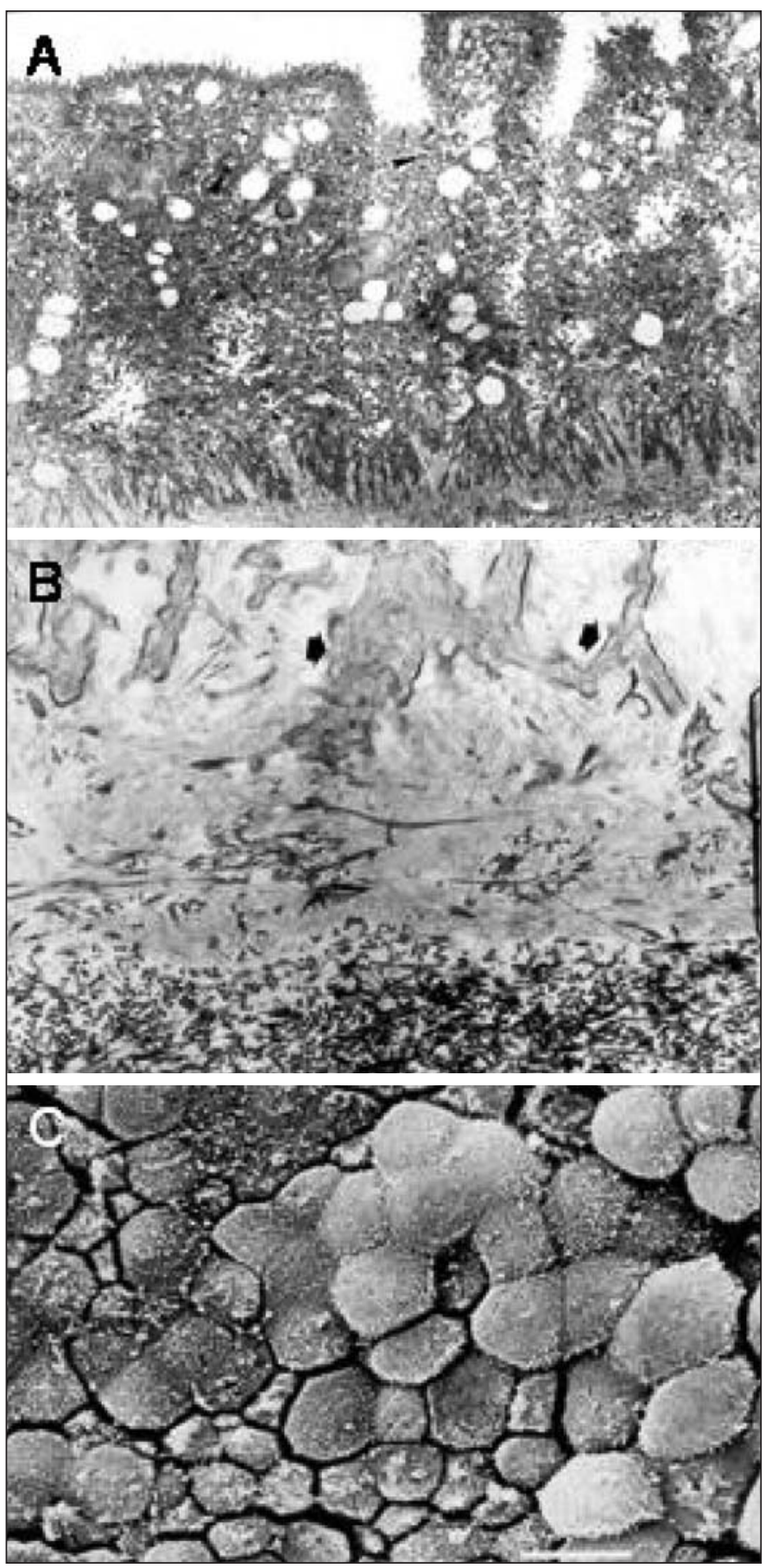

Figura 2 - Microscopia eletrônica das membranas preservadas em glicerol/MEM. Em A e B, microscopia eletrônica de transmissão; em C, microscopia eletrônica de varredura.

A maioria dos métodos empregados na preservação da membrana amniótica altera sua característica de alguma forma. Análises da membrana amniótica preservada em glicerol e congelada a $-80^{\circ} \mathrm{C}$ mostraram manutenção da estrutura em comparação com a membrana fresca. No entanto, foi constatada perda da viabilidade das células epiteliais após serem submetidas a essa temperatura. Eles concluíram que o efeito 

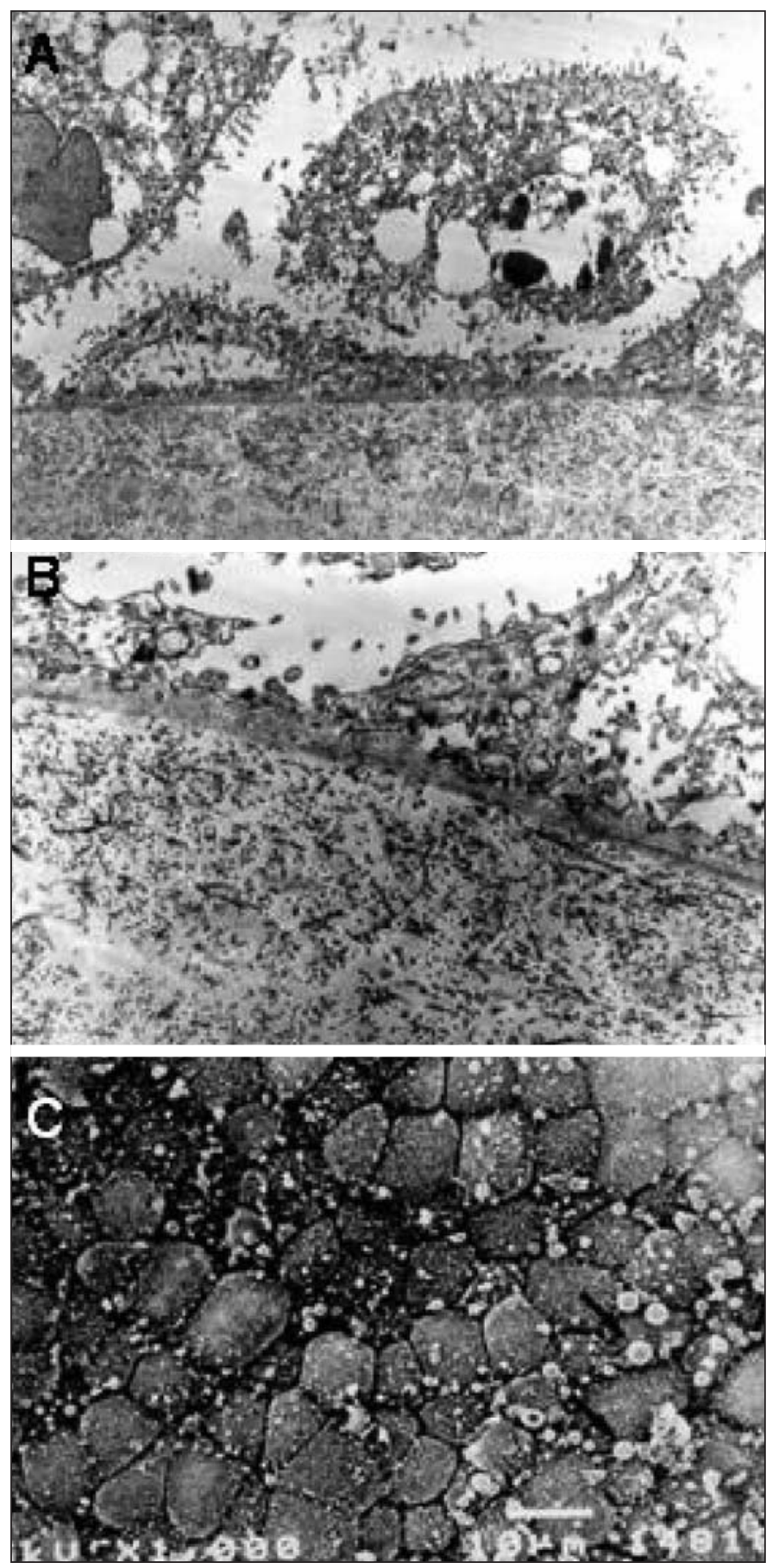

Figura 3 - Microscopia eletrônica das membranas preservadas em DMSO. Em A e B, microscopia eletrônica de transmissão; em C, microscopia eletrônica de varredura.

da membrana amniótica decorre de sua propriedade de matriz e não das suas células ${ }^{(26)}$. Alguns autores mostraram que após 2 meses de congelamento, $50 \%$ das células amnióticas são viáveis e capazes de proliferar ${ }^{(27)}$. Após 18 meses, não havia mais células viáveis. Um outro estudo mostrou não haver diferenças entre várias técnicas de esterilização e preservação da membrana amniótica, incluindo glicerol, mas não $\mathrm{DMSO}^{(28)}$.

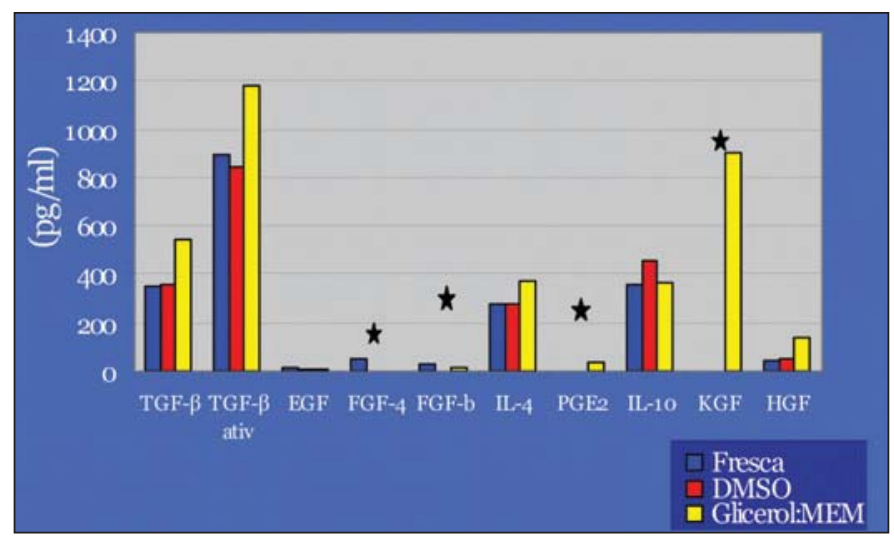

Figura 4- Fatores de crescimento e citocinas comparando os grupos controle, glicerol/MEM e DMSO. TGF- $\beta$ : fator transformador de crescimento $\beta$; TGF- $\beta$ ativ: fator transformador de crescimento $\beta$ ativado; EGF: fator recombinante de crescimento epitelial humano; FGF-4: fator de crescimento fibroblástico 4; FGF-b: fator de crescimento fibroblástico

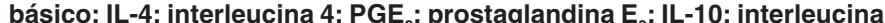
10; KGF: fator de crescimento de queratinócito; HGF: fator de crescimento de hepatócito. ${ }^{*} \mathrm{p}<0,05$.

Outros autores usaram glutaraldeído e radiação gama na membrana amniótica. Eles mostraram que a radiação degradava a membrana in vitro em comparação com a mantida em meio químico $^{(29)}$. Essas evidências suportam que a viabilidade celular da membrana amniótica não é essencial para sua efetividade biológica.

Os resultados do nosso estudo demonstraram melhor preservação tecidual mantida em meio glicerol/MEM (1:1) em comparação com o DMSO puro, quando conservados a $-80^{\circ} \mathrm{C}$. Esse resultado não foi pior do que nas membranas frescas.

$\mathrm{O}$ uso de membrana fresca tem algumas limitações, sendo duas as principais: a necessidade de rápida utilização e a impossibilidade de obter total segurança quanto a certas infecções, como pelo HIV e hepatite $\mathrm{C}$, devido à janela imunológica.

$\mathrm{O}$ glicerol tem propriedades antiviral e antibateriana que são dependentes da concentração, tempo e temperatura ${ }^{(30-33)}$. Também foi demonstrado que o armazenamento de pele de cadáver infectada com HIV-1 em glicerol $85 \%$ a $4^{\circ} \mathrm{C}$ resultou em completa inativação do vírus após 5 dias. Esses detalhes dão ao glicerol vantagens adicionais sobre os outros métodos de preservação.

Em relação às citocinas e fatores de crescimento, estudos em membrana amniótica preservada a $-80^{\circ} \mathrm{C}$ por 1 mês revelaram a presença de EGF, TGF- $\alpha$, KGF, HGF, FGF-b, TGF- $\beta 1$ e $\beta 2$ por RT-PCR para RNAm e por ELISA para os produtos protéicos ${ }^{(19)}$. Um número maior de fatores de crescimento foi encontrado na membrana amniótica com epitélio do que na desepitelizada, indicando possível origem epitelial ${ }^{(19)}$. A expressão simultânea dos fatores e seus receptores suportam a hipótese de que o TGF- $\beta$ pode ter um papel importante em regular crescimento, diferenciação e a função da placenta humana ${ }^{(20)}$. Como, em nosso estudo, a maioria das citocinas e dos fatores de crescimento estavam presentes nas membranas preservadas em DMSO e glicerol/MEM, não acreditamos que 
uma das técnicas seja mais vantajosa que a outra. Além disso, preservaram as características da membrana amniótica fresca.

\section{CONCLUSÃO}

Em suma, a membrana amniótica preservada em meio glicerol/MEM apresentou melhor integridade tecidual, com menor desprendimento do epitélio da membrana basal, em comparação com a preservada no DMSO puro. Os fatores de crescimento e citocinas estavam, em sua maior parte, preservados com as duas técnicas de preservação.

\section{ABSTRACT}

Purpose: To compare the anatomical structure and the presence of growth factors and cytokines of amniotic membrane preserved in glycerol/MEM (1:1) or undiluted dimethyl sulfoxide through electron microscopy. Methods: Amniotic membrane preserved in glycerol/MEM (1:1) or undiluted dimethyl sulfoxide were processed for transmission and scaning electron microscopy. As control, freshly collected amniotic membrane was fixed and processed for electron microscopy. The cytokines and growth factors assessed were: TGF- $\beta$ (transforming growth factor $\beta$ ); TGF- $\beta$ activ (activated transforming growth factor $\beta$ ); EGF (epidermal growth factor); FGF-4 (fibroblast growth factor 4); bFGF (basic fibroblast growth factor); IL-4 (interleukin 4); $\mathrm{PGE}_{2}$ (prostaglandin $\mathrm{E}_{2}$ ); IL-10 (interleukin 10); KGF (keratinocyte growth factor); HGF (hepatocyte growth factor). Results: Amniotic membrane from the control group showed intact epithelium, with surface microvilli and junctional complexes between the cells and the basal membrane. Glycerol/MEM preserved amniotic membrane had similar aspect to the control, with higher epithelial cells. Those amniotic membranes preserved in dimethyl sulfoxide disclosed less intercellular junction and detachment of the epithelium from the basal membrane. The cytokines and growth factors did not disclose significant differences, except for FGF-4, bFGF, PGE 2 and KGF. Conclusions: Amniotic membrane preserved in glycerol/MEM showed a better tissue structure, with less detachment of the epithelium from the basal membrane, in comparison to undiluted dimethyl sulfoxide. The majority of the growth factors and cytokines were kept with both techniques of preservation.

Keywords: Amnion; Microscopy, electron; Glycerol; Dimethyl sulfoxide; Cytokines; Transforming growth factor beta

\section{REFERÊNCIAS}

1. Dua HS, Azuara-Blanco A. Amniotic membrane transplantation. Br J Ophthalmol. 1999;83(6):748-52.

2. Chen HJ, Pires RT, Tseng SC. Amniotic membrane transplantation for severe neurotrophic corneal ulcers. Br J Ophthalmol. 2000;84(8):826-33.
3. Dua HS, Gomes JA, King AJ, Maharajan VS. The amniotic membrane in ophthalmology. Surv Ophthalmol. 2004;49(1):51-77.

4. Meller D, Tseng SC. [Amniotic membrane transplantation with or without limbal allografts in corneal surface reconstruction in limbal deficiency]. Ophthalmology. 2000;97(2):100-7. German.

5. Prabhasawat P, Barton K, Burkett G, Tseng SC. Comparison of conjunctival autografts, amniotic membrane grafts, and primary closure for pterygium excision. Ophthalmology. 1997;104(6):974-85.

6. Shimazaki J, Shinozaki N, Tsubota K. Transplantation of amniotic membrane and limbal autograft for patients with recurrent pterygium associated with symblepharon. Br J Ophthalmol. 1998;82(3):235-40.

7. Gomes JAP, Fernandes LH, Komagome CM, Höfling-Lima AL, Prata Junior JA. Uso de membrana amniótica no tratamento de complicaçöes pós-trabeculectomia. Arq Bras Oftalmol. 2001;64(5):437-41.

8. Tseng SC, Prabhasawat P, Lee SH. Amniotic membrane transplantation for conjunctival surface reconstruction. Am J Ophthalmol. 1997;124(6):765-74.

9. Kim JC, Tseng SC. Transplantation of preserved human amniotic membrane for surface reconstruction in severely damaged rabbit corneas. Cornea. 1995;14 (5):473-84

10. Tsubota K, Satake Y, Ohyama M, Toda I, Takano Y, Ono M, et al. Surgical reconstruction of the ocular surface in advanced ocular cicatricial pemphigoid and Stevens-Johnson syndrome. Am J Ophthalmol. 1996;122(1):38-52.

11. Shimazaki J, Yang HY, Tsubota K. Amniotic membrane transplantation for ocular surface reconstruction in patients with chemical and thermal burns. Ophthalmology. 1997;104(12):2068-76. Comment in: Ophthalmology. 2000; 107(3):411-2.

12. Tseng SC, Prabhasawat P, Barton K, Gray T, Meller D. Amniotic membrane transplantation with or without limbal allografts for corneal surface reconstruction in patients with limbal stem cell deficiency. Arch Ophthalmol. 1998; 116(4):431-41.

13. Gruss JS, Jirsch DW. Human amniotic membrane: a versatile wound dressing. Can Med Assoc J. 1978;118(10):1237-54.

14. Mathews RN, Faulk WP, Bennett JP. A review of the role of amniotic membranes in surgical practice. Obstet Gynecol Annu. 1982;11:31-58.

15. Colocho G, Graham WP, $3^{\text {rd }}$, Greene AE, Matheson DW, Lynch D. Human amniotic membrane as physiologic wound dressing. Arch Surg. 1974;109(3): 370-3.

16. Fujishima H, Shimazaki J, Shinozaki N, Tsubota K. Trabeculectomy with the use of amniotic membrane for uncontrollable glaucoma. Ophthalmic Surg Lasers. 1998;29(5):428-31.

17. Grant MB, Khaw PT, Schultz GS, Adams JL, Shimizu RW. Effects of epidermal growth factor, fibroblast growth factor, and transforming growth factor- $\beta$ on corneal cell chemotaxis. Invest Ophthalmol Vis Sci. 1992;33(12): 3292-301.

18. Wilson SE, Schultz GS, Chegini N, Weng J, He YG. Epidermal growth factor, transforming growth factor beta, acidic fibroblast growth factor, basic fibroblast growth factor and interleukin-1 proteins in the cornea. Exp Eye Res. 1994;59(1):63-72.

19. Koizumi N, Inatomi T, Sotozono C, Fullwood NJ, Quantock AJ, Kinoshita $\mathrm{S}$. Growth factors mRNA and protein in preserved amniotic membrane. Curr Eye Res. 2000;20(3):173-7.

20. Schilling B, Yeh J. Transforming growth factor-beta(1), -beta(2), -beta(3) and their type I and II receptors in human term placenta. Gynecol Obstet Invest. 2000;50(1):19-23.

21. Hao Y, Ma DH, Hwang DG, Kim WS, Zhang F. Identification of antiangiogenic and antiinflammatory proteins in human amniotic membrane. Cornea. 2000;19(3):348-52.

22. Paradowska E, Blach-Olszewska Z, Gejdel E. Constitutive and induced cytokine production by human placenta and amniotic membrane at term. Placenta. 1997; 18(5-6):441-6.

23. Fortunato SJ, Menon R, Swan KF, Lombardi SJ. Interleukin-10 inhibition of interleukin-6 in human amniochorion membrane: transcriptional regulation. Am J Obst Gynecol. 1996;175(4 Pt 1):1057-65.

24. Trautman MS, Collmer D, Edwin SS, White W, Mitchell MD, Dudley DJ. Expression of interleukin-10 in human gestacional tissues. J Soc Ginecol Investig. 1997;4(5):247-53.

25. Shimmura S, Shimazaki J, Ohashi Y, Tsubota K. Antiinflammatory effects of amniotic membrane transplantation in ocular surface disorders. Cornea. 2001; 20(4):408-13.

26. Kruse FE, Joussen AM, Rohrschneider K, You L, Sinn B, Baumann J, et al. Cryopreserved human amniotic membrane for ocular surface reconstruction. Graefes Arch Clin Exp Ophthalmol. 2000;238(1):68-75.

27. Kubo M, Sonoda Y, Muramatsu R, Usui M. Immunogenicity of human 
amniotic membrane in experimental xenotransplantation. Invest Ophthalmol Vis Sci. 2001;42(7):1539-46.

28. von Versen-Hoynck F, Syring C, Bachmann S, Moller DE. The influence of different preservation and sterilisation steps on the histological properties of amnion allografts-light and scanning electron microscopic studies. Cell Tissue Bank. 2004;5(1):45-56.

29. Fujisato T, Tomihata K, Tabata Y, Iwamoto Y, Burczak K, Ikada Y. Crosslinking of amniotic membranes. J Biomater Sci Polym Ed. 1999;10(11):1171-81. 30. Maral T, Borman H, Arslan H, Demirhan B, Akinbingol G, Haberal M.
Effectiveness of human amnion preserved long-term in glycerol as a temporary biological dressing. Burns. 1999;25(7):625-35.

31. Marshall L, Ghosh MM, Boyce SG, MacNeil S, Freedlander E, Kudesia G. Effects of glycerol on intracellular virus survival: implications for the clinical use of glycerol-preserved cadaver skin. Burns. 1995;21(5):356-61.

32. van Baare J, Ligtvoet EEJ, Middelkoop E. Microbiological evaluation of glycerolized cadaveric donor skin. Transplantation. 1998;65(7):966-70.

33. van Baare J, Buitenwerf J, Hoekstra MJ, du Pont JS. Virucidal effect of glycerol as used in donor skin preservation. Burns. 1994;20(Suppl 1):S77-80. 